\title{
Refractive outcomes after trabecular microbypass stent with cataract extraction in open-angle glaucoma
}

This article was published in the following Dove Press journal: Clinical Ophthalmology

\author{
Rachel A Scott ${ }^{1}$ \\ Tanner J Ferguson ${ }^{2}$ \\ John D Stephens ${ }^{3}$ \\ John P Berdahl ${ }^{3}$
}

'Baylor College of Medicine, Houston, TX, USA; ${ }^{2}$ Sanford School of Medicine, University of South Dakota, Vermillion, SD, USA; ${ }^{3}$ Vance Thompson Vision, Sioux Falls, SD, USA
Correspondence: Rachel A Scott Baylor College of Medicine, I Baylor Plaza, Houston, TX 77030, USA Email rsI4@bcm.edu
Purpose: To evaluate the impact of trabecular microbypass stents combined with cataract surgery on refractive outcomes in patients with open-angle glaucoma (OAG).

Setting: Private practice, Sioux Falls, South Dakota, USA.

Design: Retrospective, comparative case series.

Methods: Eyes with OAG had implantation of trabecular microbypass stents with concomitant cataract surgery. The unmatched control group comprised eyes that underwent only cataract extraction. Data were collected preoperatively and postoperatively for 6 months. Data included spherical equivalent (SE), astigmatic error, intraocular pressure (IOP), and number of glaucoma medications.

Results: The series included 76 consecutive OAG eyes with combined cataract plus trabecular microbypass stent and 50 consecutive non-OAG eyes with cataract surgery only. SE outcomes were equivalent between the groups $(P<0.001)$. For the combined and cataractonly groups respectively, $46 \%$ vs $52 \%$ had SEs within $0.25 \mathrm{D}$ of the target, $80 \%$ vs $80 \%$ within $0.50 \mathrm{D}$, and $95 \%$ vs $94 \%$ within $1.00 \mathrm{D}$. Astigmatism outcomes did not significantly differ between the groups $(P>0.05)$. As for magnitude of astigmatism in the combined and cataract only groups respectively, $51 \%$ vs $32 \%$ were within $0.5 \mathrm{D}, 75 \%$ vs $66 \%$ within $1.0 \mathrm{D}$, $87 \%$ vs $82 \%$ within $1.5 \mathrm{D}$, and $89 \%$ vs $94 \%$ within $2.0 \mathrm{D}$. In the OAG combined-surgery group, mean intraocular pressure reduction was $3.4 \mathrm{mmHg}(P<0.0001)$ at 1 month postoperatively, $4.0 \mathrm{mmHg}(P<0.0001)$ at 3 months, and $3.4 \mathrm{mmHg}(P<0.01)$ at 6 months. Mean decrease in number of glaucoma medications was $0.4(P<0.05)$ at 1 month, $0.7(p<0.0001)$ at 3 months, and $0.9(P<0.001)$ at 6 months.

Conclusion: The results of this study suggest the trabecular microbypass stent is a refractively neutral device.

Keywords: MIGS, glaucoma, refractive, outcomes, cataract surgery

\section{Introduction}

Glaucoma is the second-leading cause of blindness worldwide, and as the number of people affected by this disease continues to rise, it becomes an even more pressing public health problem. ${ }^{1,2}$ As severity increases, cost of care increases. ${ }^{3,4}$ Therefore, it is important glaucoma be treated early and effectively to halt disease progression and reduce the economic and personal burden on patients. The advent of minimally invasive glaucoma surgery (MIGS) and the plethora of options have provided an opportunity for safer interventional treatments earlier in the disease, and these procedures are often performed in combination with cataract surgery. ${ }^{5}$ 
The iStent (Glaukos, San Clemente, CA, USA), the first US Food and Drug Administration-approved MIGS device, is a trabecular microbypass stent designed to bypass the trabecular meshwork to augment physiological outflow to Schlemm's canal and lower intraocular pressure (IOP). ${ }^{6}$ The safety and efficacy of the iStent alone, ${ }^{7-9}$ as well as when combined with cataract surgery, ${ }^{10-13}$ has been well established in the literature. Recently, a large study by Manoharan et al demonstrated that refractive surprise is more common in glaucoma patients having cataract surgery, in particular those with angle-closure and pseudoexfoliation glaucoma. It remains unclear whether this increased incidence of refractive surprise is secondary to ocular surface disease, an alteration of effective lens position, or other etiology. ${ }^{14}$ However, in subgroup analysis of cataract surgery combined with MIGS in primary open-angle glaucoma (OAG eyes) compared to nonglacuoma eyes, Manoharan et al did not find a significant difference in refractive surprise. Worth noting, this subgroup included eyes with microbypass stent, endoscopic cyclophotocoagulation (ECP), and both microbypass stent and ECP. To our knowledge, while the aforementioned study by Manoharan et al included a subset of eyes with combined iStent and phacoemulsification, this is the first study exclusively to study the refractive outcomes of combined iStent and phacoemulsification.

Previous studies have reported higher incidence of refractive surprise following cataract surgery in glaucoma patients compared to controls without glaucoma. ${ }^{14}$ Currently, there is substantial evidence showing that trabeculectomy is associated with significant with-the-rule astigmatic change, as well as increased refractive surprise. ${ }^{15-20}$ Moreover, studies investigating both trabeculectomy and glaucoma-drainage devices, such as tube shunts, have found decreases in axial length, as well as a trend of more induced cylinder and more induced myopia, ${ }^{21-23}$ suggesting that these more invasive glaucoma surgeries are not refractively neutral. However, Hammel et al investigated the impact of Ex-Press implant (Alcon, Fort Worth, TX, USA) surgery, and found that the transient increase in corneal astigmatism, both anterior and posterior, resolved by 3 months. ${ }^{24}$

The limited research evaluating the impact of MIGS devices on refractive outcomes has been promising. Although the supraciliary microstent (CyPass; Alcon) is no longer available, due to long-term safety concerns, there was prior discussion regarding myopic shift associated with the device; however, a retrospective review presented by Flowers demonstrated no significant impact on refractive outcomes. ${ }^{25}$ To our knowledge, the impact of combined cataract surgery with trabecular microbypass-stent implantation on refractive outcomes has not yet been established. The present study aimed to investigate refractive outcomes after trabecular microbypass stent with combined cataract surgery in eyes with OAG.

\section{Methods}

\section{Study design}

This retrospective comparative study was comprised of a consecutive case series of patients undergoing combined cataract surgery and implantation of a trabecular microbypass stent from January 2017 to September 2017 compared to 50 patients having cataract surgery during the same time frame. All patients in the combined cataract surgery and trabecular microbypass-stent group had been diagnosed with mild-severe OAG. Stage of disease was based on visual field criteria and/or optic nerve-head changes, consistent with the American Academy of Ophthalmology Preferred Practice Pattern Guidelines. ${ }^{26}$ Gonioscopy was performed on each trabecular microbypass-stent patient to ensure adequate visualization of the angle for implantation of the device. The inclusion criterion in the combined cataract surgery and trabecular microbypass-stent group was the presence of OAG. There were no strict inclusion criteria for the cataract-surgery group, and 50 consecutive eyes were included. Eyes that were missing refractions were excluded. This study collected and evaluated data from procedures performed by the same surgeon (JPB) at a single site (Vance Thompson Vision, Sioux Falls, SD, USA), and was approved by the University of South Dakota Institutional Review Board. Informed consent was waived by the University of South Dakota, as all data collected were deidentified and included no more information than would normally be collected for this procedure.

\section{Surgical technique}

Cataract extraction was performed similarly in both groups with $2.4 \mathrm{~mm}$ temporal clear corneal incisions. In those receiving a trabecular microbypass stent, once the intraocular lens had been inserted, the microscope and patient's head were rotated approximately $30^{\circ}$ away from the surgeon. With the nondominant hand, a gonioprism was held on the cornea and the trabecular meshwork brought into focus. With a preloaded injector, the trabecular microbypass stent was inserted through the clear corneal incision. The 
stent, on the tip of the inserter, was guided at a $20^{\circ}$ angle into the trabecular meshwork and advanced inferiorly. The stent was released and the shaft of the insertion device used to push the heel of the device into the trabecular meshwork. Through "strumming" the device with the injector tip in a posterior-to-anterior direction, secure placement of the device was confirmed. The stent was repositioned if it had not been properly secured. In case where a region of pigmentation was noted on intraoperative gonioscopy, that region was targeted for placement.

\section{Postoperative medications and follow-up}

Postoperatively, patients were prescribed a drop regimen as follows: moxifloxacin $0.05 \%$ for 1 week, a daily NSAID (bromefenac $0.07 \%$ or nepafenac $0.3 \%$ ) for 4 weeks, and a topical steroid (difluprednate $0.05 \%$ or prednisolone acetate $1 \%$ ) for 4 weeks. The steroid therapy was initiated at four times per day and tapered to twice per day after 7 days. Patients kept on using their preoperative ocular hypotensive medications for at least 1 week or until the operating physician deemed the patient's IOP clinically acceptable. If there was progression of nerve-fiber loss on optical coherence tomography, progression of glaucomatous visual field loss, or a clinical judgment that the IOP level would likely cause either parameter to progress, postoperative medical therapy was escalated.

\section{Outcome measurements}

The main outcome measures in the study were refractive outcomes, specifically the difference between target spherical equivalent (SE) and postsurgery SE between 1 and 3 months, as well as the difference in astigmatism pre- and postsurgery. Preoperative astigmatism was collected by dual-zone keratometry (Lenstar; Haag-Streit, Berne, Switzerland). Postoperative astigmatism was determined by manifest refraction. Intraocular lenses used in each of the two groups were recorded. Secondary outcome measures for the combined group included IOP and number of glaucoma medications. Notably, combination medications were reported as two medications. Preoperative IOP was obtained in the visit immediately prior to surgery and based on a single measure.

Preoperative data were used to establish a baseline, which typically occurred in the visit immediately before surgery. Postoperatively, data were collected from the following time points to compare with baseline data: 1 day, 1 week, 1 month, 3 months, and 6 months. At each time point, the data collected included IOP, number, and type of medications used, and manifest refraction was obtained at certain time points.

\section{Statistical analyses}

XLStat version 2018.6 was used for statistical analyses. SE refractive outcome was calculated as the difference between the postoperative SE and target SE and divided into the percentage within $0.25 \mathrm{D}, 0.50 \mathrm{D}$, and $1.00 \mathrm{D}$ of the target. These results were compared to benchmark standards for refractive outcomes after cataract surgery, in addition to the cataract-only control group. A two onesided test (TOST) equivalence test using upper and lower bounds of 0.25 (the smallest diopter unit able to be measured) was used to determine equivalence of SE outcomes between the combined and cataract-only surgery groups. Astigmatism outcomes were measured using American Society of Cataract and Refractive Surgery's Astigmatism Double Angle Plot Tool version 1.1.0. ${ }^{27}$ With this tool, preoperative corneal astigmatism is compared to postoperative refractive astigmatism. An independent $t$-test was used to compare astigmatism outcomes after the combined surgery to those after cataract surgery alone. A parametric paired $t$-test was used to determine the significance of the mean change in IOP from baseline to 1 month, 3 months, and 6 months. A parametric paired $t$-test was also used to determine the significance of the mean change in number of glaucoma medications from baseline to 1 month, 3 months, and 6 months. An $\alpha$-level of 0.05 was considered statistically significant.

\section{Results}

A total of 76 eyes from 43 patients with OAG who had had concomitant cataract surgery with microbypass stent were retrospectively analyzed, as were 50 eyes from 26 patients without OAG who had had only cataract surgery. Five of 81 eyes, or $6.2 \%$ of eyes, were excluded from the combined group on the basis of missing refractions. The mean age was 70.0 years for the cataract surgery with microbypass-stent group, with 47 female and 29 male subjects. The mean age was 70.4 years for the cataract-only group, with 39 female and 11 male subjects. Demographic data arepresented in Table 1.

$\mathrm{SE}$ outcomes were calculated using manifest refraction obtained between 1 and 3 months after surgery. In patients with concomitant cataract surgery with trabecular microbypass stent ( $\mathrm{n}=76$ ), 46\% (35 of 76) had SEs within $0.25 \mathrm{D}$, $80 \%$ (61 of 76) had SEs within $0.50 \mathrm{D}$, and 95\% (72 of 76) had SEs within $1.00 \mathrm{D}$ of the target. In the control group (cataract extraction only), refractive outcomes between 1 and 
Table I Demographics for cataract + trabecular microbypassstent group and cataract-only group

\begin{tabular}{|l|l|l|}
\hline & $\begin{array}{l}\text { Cataract + trabecular } \\
\text { microbypass stent }\end{array}$ & $\begin{array}{l}\text { Cataract } \\
\text { only }\end{array}$ \\
\hline Eyes, $\mathrm{n}$ & 76 & 50 \\
Age (years) & 70.03 & 70.42 \\
Female:male & $47: 29$ & $39: 11$ \\
\hline Open-angle glaucoma & $100 \%$ & 0 \\
Severe & $5.3 \%$ & \\
Moderate & $13.2 \%$ & \\
Mild & $81.5 \%$ & \\
\hline
\end{tabular}

3 months $(n=50)$ were $52 \%$ (25 of 50$)$ of patients with SEs within $0.25 \mathrm{D}, 80 \%$ (40 of 50) with SEs within $0.50 \mathrm{D}$, and $94 \%$ (47 of 50) with SEs within $1.00 \mathrm{D}$ of the target. These results are shown in Figure 1. A TOST equivalence test showed that the two groups had equivalent SE outcomes $\left(\mathrm{t}_{124} 4.5, P<0.0001\right)$.

The magnitude of preoperative corneal astigmatism and postoperative refractive astigmatism can be seen in Figure 2 for the combined cataract and trabecular microbypass group and Figure 3 for the cataract-only group. Preoperative and postoperative astigmatic vectors and their means and spread are illustrated in the double-angle plots in Figures 4 and 5 for the combined-surgery and cataract-only surgery groups, respectively. For the combined surgery group, the preoperative centroid was $0.31 \mathrm{D}$ at $90^{\circ} \pm 1.35 \mathrm{D}$ and the mean absolute $1.14 \pm 0.78$ D. The postoperative centroid was $0.08 \mathrm{D}$ at $92^{\circ} \pm 1.05 \mathrm{D}$ and the mean absolute $0.69 \pm 0.78 \mathrm{D}$. For the cataract surgery-only group, the preoperative centroid was $0.51 \mathrm{D}$ at $96^{\circ} \pm 1.78 \mathrm{D}$ and the mean absolute 0.82 $\pm 1.63 \mathrm{D}$. The postoperative centroid was $0.22 \mathrm{D}$ at $173^{\circ} \pm$ $1.12 \mathrm{D}$ and the mean absolute $0.94 \pm 0.64 \mathrm{D}$. Comparison of the postoperative mean absolute of the combined-procedure group to the cataract-only group showed no significant difference in astigmatism outcome $(P>0.05)$. The distribution of different lens types (monofocal, multifocal, and toric) for each group is illustrated in Figure 6.

In the OAG combined group, there was a significant IOP reduction at the 1-week, 1-month, 3-month, and 6month time points compared to the preoperative baseline. Compared to a baseline mean of $18.7 \pm 5.8 \mathrm{mmHg}$, the mean IOP reduction was $2.0 \mathrm{mmHg}(P<0.05)$ at 1 week, $3.4 \mathrm{mmHg}(P<0.0001)$ at 1 month, $4.0 \mathrm{mmHg}(P<0.0001)$ at 3 months, and $3.4 \mathrm{mmHg}(P<0.01)$ at 6 months. These results are shown in Figure 7.

In regard to hypotensive medication use in the OAG combined group, there was a statistically significant reduction

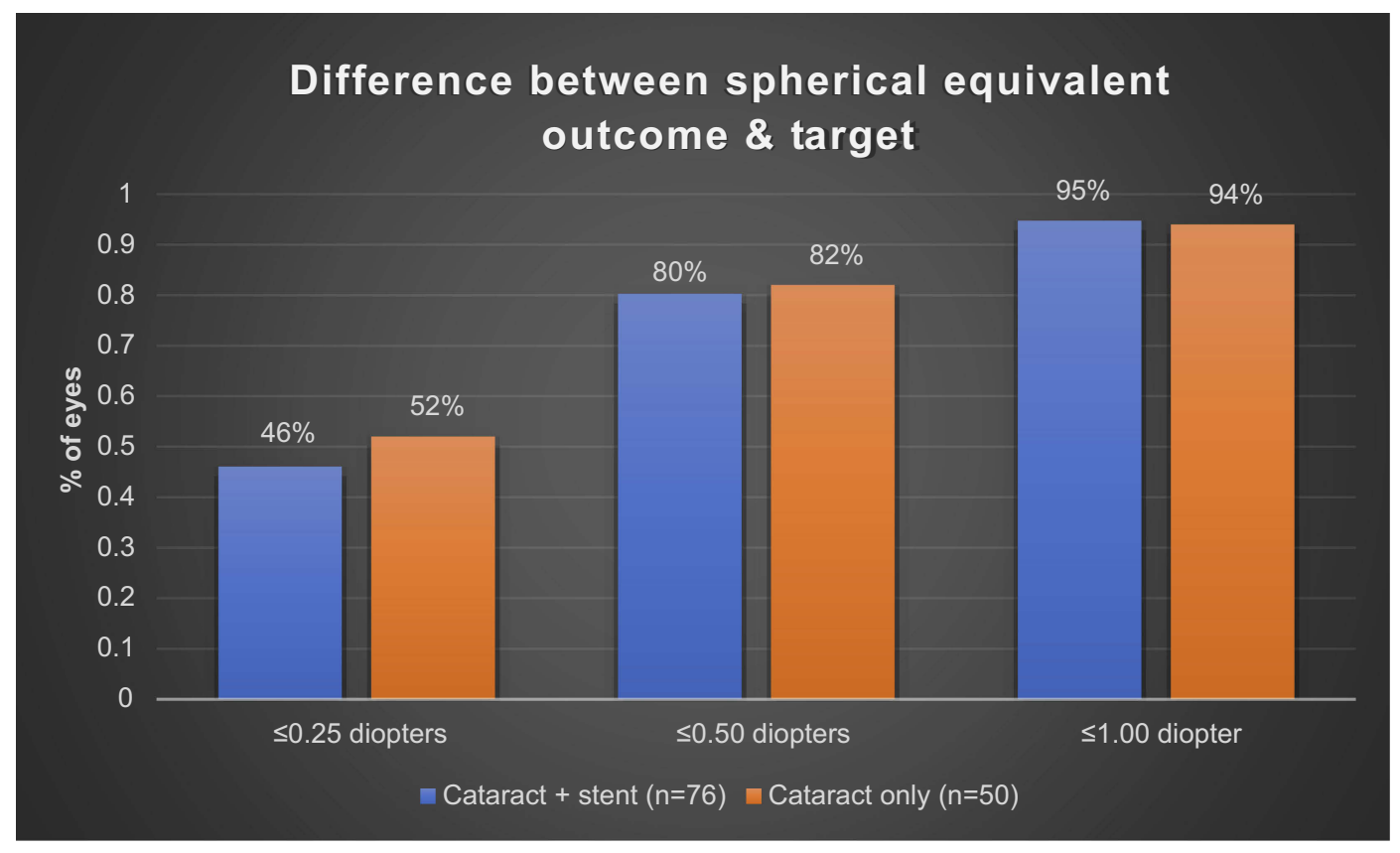

Figure I Difference between spherical equivalent outcome and target.

Notes: Ratio of cases with spherical equivalent outcome within a certain number of designated diopters of target spherical equivalent. Blue bars represent cataract-only cases. Orange bars represent cases of cataract surgery with trabecular microbypass stent. TOST equivalence testing showed the spherical outcomes of the two groups were equivalent $\left(t_{124}=4.5, P<0.000 \mathrm{I}\right)$.

Abbreviation: TOST, two one-sided test. 


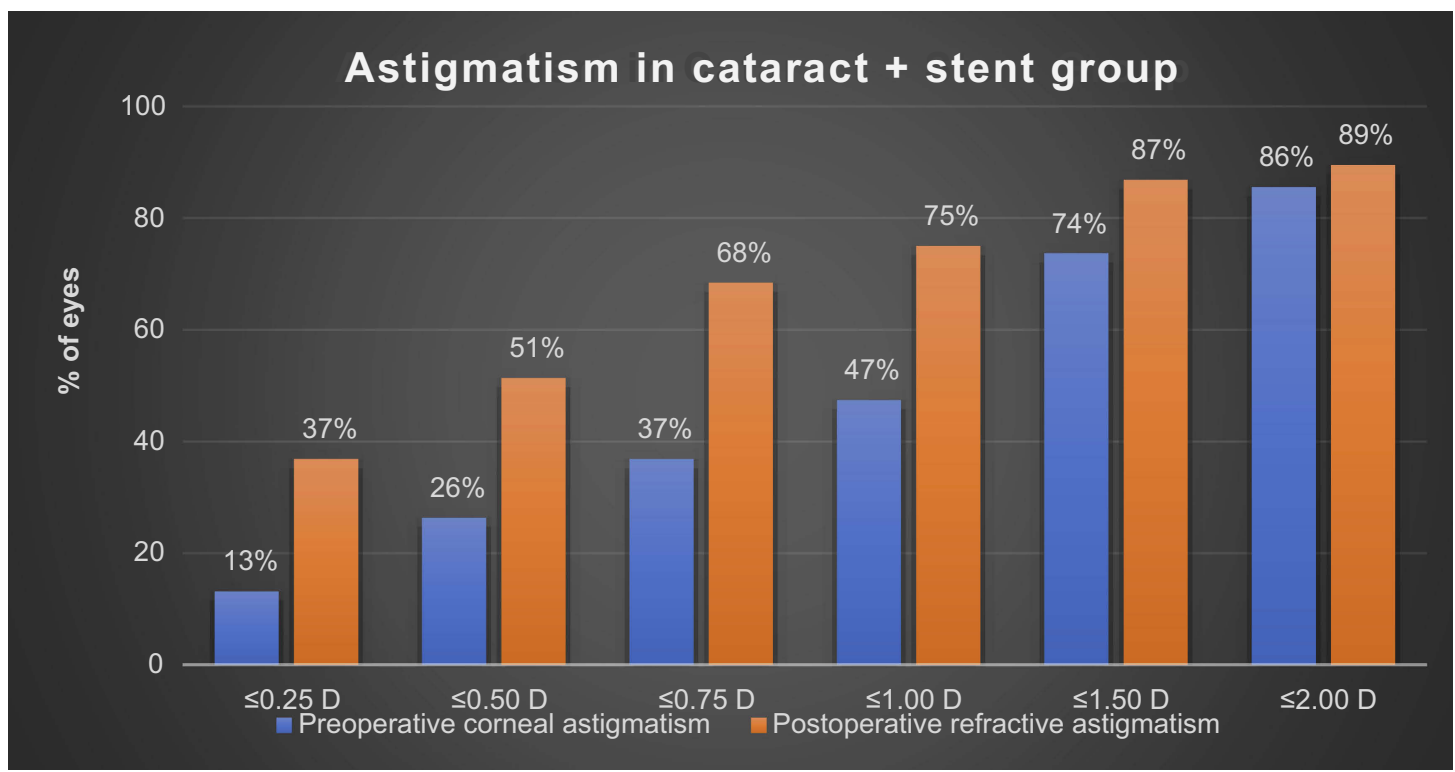

Figure 2 Magnitude of preoperative corneal astigmatism and postoperative refractive astigmatism in patients with combined cataract surgery with trabecular microbypass stent.

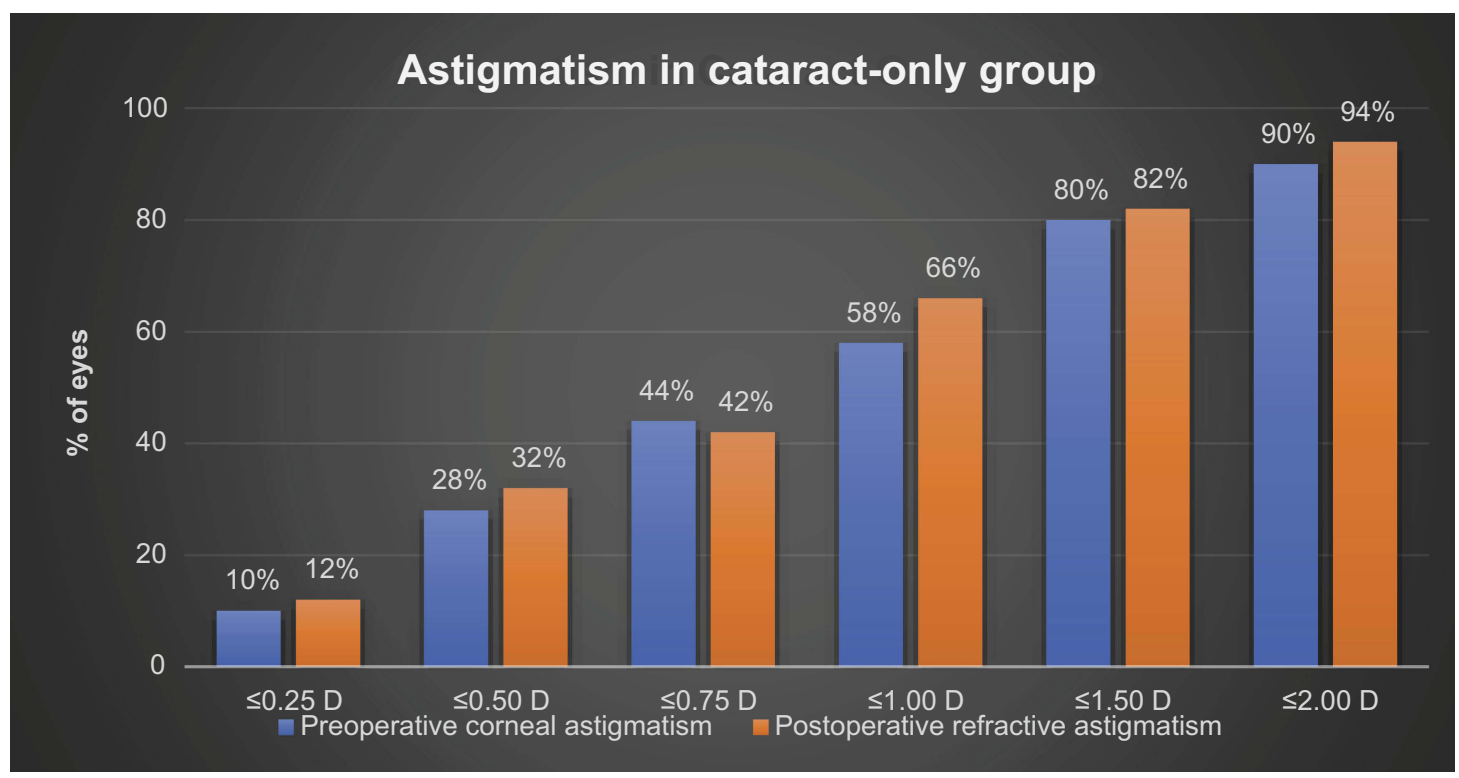

Figure 3 Magnitude of preoperative corneal astigmatism and postoperative refractive astigmatism in patients with cataract surgery only.

at the 1-month, 3-month, and 6-month postoperative visits compared to the preoperative baseline. The preoperative baseline $1.3 \pm 1.2$ was reduced by $0.4(P<0.05)$ at 1 month, 0.7 $(P<0.0001)$ at 3 months, and $0.9(P<0.01)$ at 6 months. These results are shown in Figure 7.

\section{Discussion}

For glaucomatous treatment, numerous studies have established the safety and efficacy of the trabecular microbypass stent in combination with cataract surgery. This present study aimed to investigate the refractive impact of the trabecular microbypass stent. The results of this study produced similar refractive outcomes for cataract surgery combined with trabecular microbypass- stent placement compared to cataract surgery alone. Between 1 and 3 months, $46 \%$ of patients had SEs within $0.25 \mathrm{D}, 80 \%$ within $0.50 \mathrm{D}$, and $95 \%$ within $1.00 \mathrm{D}$ of the target. These values exceed the benchmark standards set by the UK National Health Service of 55\% within $0.50 \mathrm{D}$ and $85 \%$ within $1.00 \mathrm{D}^{28,29}$ Additionally, these results meet the new benchmark of $94 \%$ within $1.00 \mathrm{D}$ of the target proposed by Massachusetts Eye and Ear. ${ }^{30}$ In our study, the 


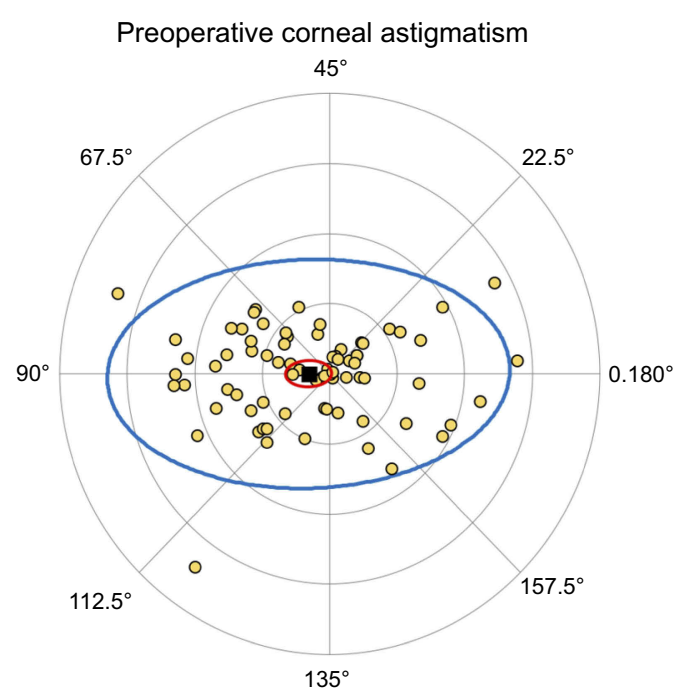

Centroid: 0.31D @ $90^{\circ} \pm 1.35 \mathrm{D}$

Mean absolute: $1.14 \mathrm{D} \pm 0.78 \mathrm{D}$

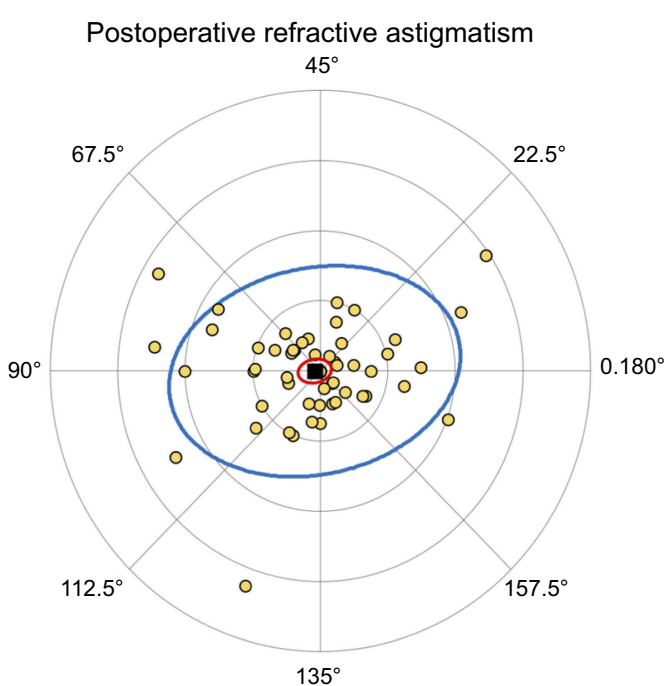

Centroid: $0.8 \mathrm{D} @ 92^{\circ} \pm 1.05 \mathrm{D}$

Mean absolute: 0.8D @ 92 $\pm 1.05 \mathrm{D}$ $n=76$

Centroid $\bigcirc 95 \%$ confidence ellipse of the centroid

$95 \%$ confidence ellipse of the data set Each ring $=1.00 \mathrm{D}$

Figure 4 Double-angle plot showing preoperative and postoperative astigmatic vectors and their means and spread for the combined cataract surgery with trabecular microbypass-stent group.

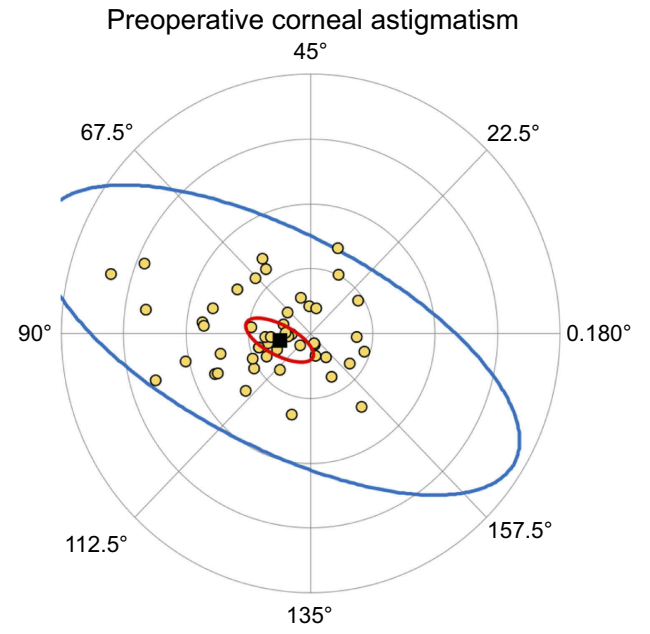

Centroid: $0.51 \mathrm{D} @ 96^{\circ} \pm 1.78 \mathrm{D}$

Mean absolute: $0.82 \mathrm{D} \pm 1.63 \mathrm{D}$

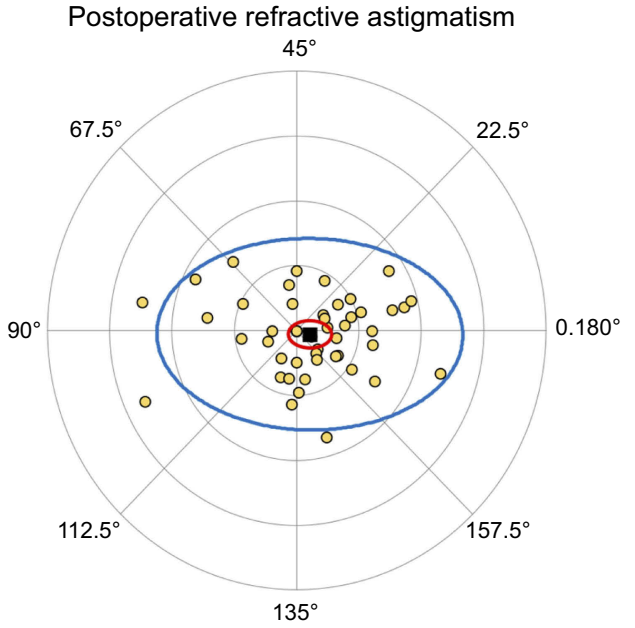

Centroid: $0.22 \mathrm{D} @ 173^{\circ} \pm 1.12 \mathrm{D}$

Mean absolute: $0.94 \mathrm{D} \pm 1.64 \mathrm{D}$ $\mathrm{n}=50$

Centroid

$95 \%$ confidence ellipse of the centroid

$95 \%$ confidence ellipse of the data set Each ring $=1.00 \mathrm{D}$

Figure 5 Double-angle plot showing preoperative and postoperative astigmatic vectors and their means and spread for the cataract surgery-only group.

SE results at 1-3 months in the combined-procedure group were equivalent to those of cataract surgery alone.

For magnitude of astigmatism postoperatively between 1 to 3 months, $37 \%$ of patients were within $0.25 \mathrm{D}, 51 \%$ within $0.50 \mathrm{D}, 75 \%$ within $1.00 \mathrm{D}, 87 \%$ within $1.50 \mathrm{D}$, and $89 \%$ within $2.00 \mathrm{D}$. While these results do suggest a trend of the combined procedure outperforming the cataract-only group in lower magnitude of astigmatism groupings, such as percentage within $0.25 \mathrm{D}$, overall analysis of astigmatism did not show a significant difference between the two groups. Additionally, both groups had similar distribution of intraocular lens types, suggesting that was not a confounding contributor in refractive outcomes. 


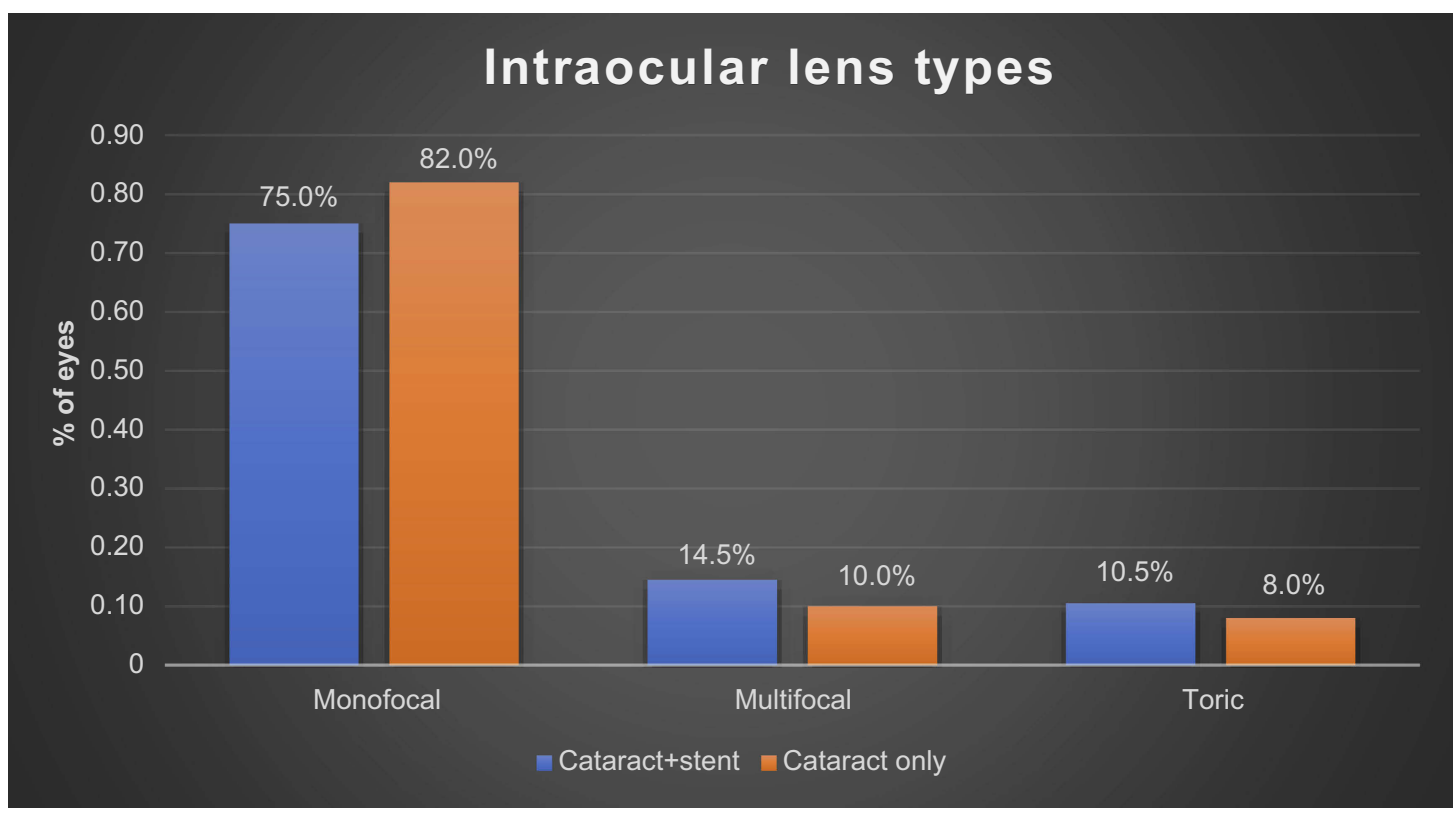

Figure 6 Distribution of different lens types (monofocal, multifocal, and toric) for the combined-surgery group and the cataract-only group.

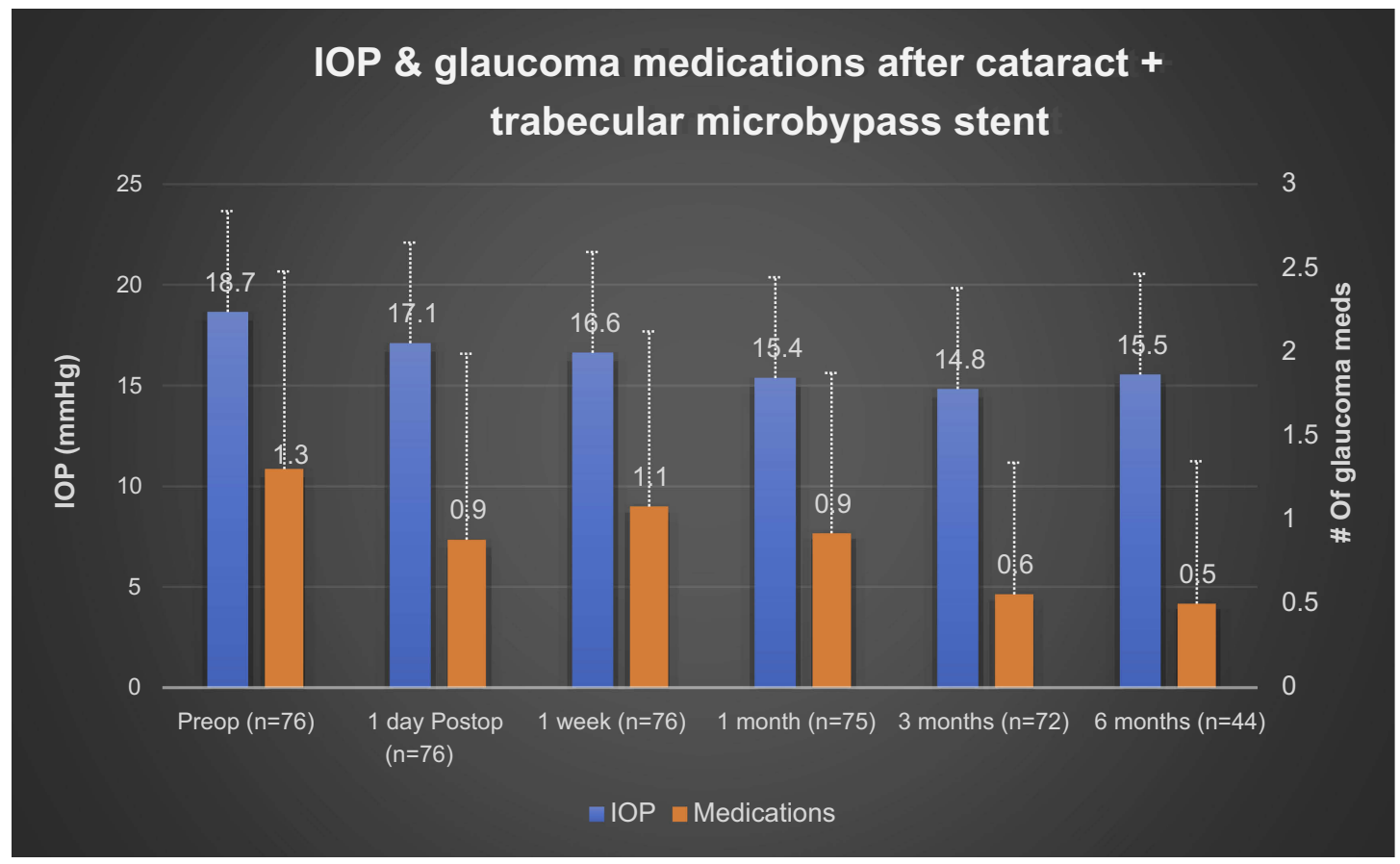

Figure 7 Mean intraocular pressure (IOP) and number of glaucoma medications from baseline to 6 months postoperatively in eyes implanted with a trabecular microbypass stent during cataract surgery.

Note: Error bars represent SD.

Manoharan et al reported an increased incidence of refractive surprise following cataract surgery in glaucoma patients compared to controls: $40.3 \%$ vs $29.9 \%$ for $>0.50$ $\mathrm{D}$ and $11.2 \%$ vs $4.9 \%$ for $>1.00 \mathrm{D}$, respectively. ${ }^{14} \mathrm{~A}$ subset of the glaucoma group in this study had combined cataract surgery and MIGS - microbypass stent, ECP, or both microbypass stent and ECP - and the results of this combined group were analyzed separately. In this subgroup analysis, Manoharan et al found a significant increase in refractive surprise in the combined cataractMIGS group compared to cataract only in nonglaucoma eyes. Interestingly, when these data were analyzed further 
by glaucoma subtype, there was not a significant increase in refractive surprise in patients with primary OAG with the combined procedure, indicating the impact of glaucoma subtype on refractive outcome. ${ }^{14}$ Sheybani et al investigated the difference between predicted and actual refractive outcomes after combined cataract surgery and ECP in patients with OAG, and found that compared to OAG patients with phacoemulsification alone, combined cataract and ECP had more myopic outcomes than predicted and also had significantly increased variability in refractive outcomes. ${ }^{31}$ This work indicates that certain MIGS procedures could actually contribute to refractive surprise in OAG patients, which is something to recognize as new devices emerge in the space. The increased variability in outcomes and myopic shift with ECP shown by Sheybani et al suggests that the difference in refractive surprise found by Manoharan et al in the combined cataract-MIGS group (8.9\%) compared to the nonglaucoma cataract group (4.9\%), while not significant, could likely be even smaller if analysis for only combined cataract and microbypass stent was done and ECP results excluded. Indeed, our own results showed a refractive surprise $>1$ $\mathrm{D}$ of $5 \%$ in the combined cataract and microbypass-stent group, which is comparable to both the nonglaucoma cataract-only group in Manoharan et al's study and our own nonglaucoma cataract-only group. Additionally, other reports have demonstrated the negative impact of more invasive glaucoma surgeries on astigmatism. ${ }^{20-22}$

However, the results of this study suggest that the combined procedure - trabecular microbypass + cataract surgery - is a favorable option in maintaining refractive outcomes similar to cataract surgery alone. Luebke et al similarly found that the combined procedure of cataract surgery with trabectomy, another MIGS procedure that uses electrocautery to permanently remove a portion of the trabecular meshwork and increase aqueous outflow, did not have significantly different refractive outcomes compared to cataract surgery alone. ${ }^{32}$ Our results add to the current growing body of literature showing minimal impact of MIGS devices on refractive outcome. ${ }^{24,25}$ The results of this study also add to the literature supporting the minimal surgical-induced astigmatism effect of cataract surgery combined with trabecular microbypass-stent insertion, showing no evidence of impaired refractive outcome with the combined procedure. Additionally, our study demonstrated a statistically significant drop in IOP and glaucoma medications consistent with previous studies evaluating the device. ${ }^{10-13}$
This study is not without limitations. The retrospective design of the study prevents uniform follow-up, which contributes to missing data at specific time points in the postoperative period, with some patients electing to follow up postoperatively at select time points, rather than all recommended standard time points used in the study. The control group consisted of 50 consecutive cases of cataract surgery alone during the same time period by the same surgeon, but was not matched in other ways. Notably, none of the control group patients had glaucoma. Additionally, the single IOP measure was a limitation in the secondary outcome analysis. Despite the limitations, this study contributes important data regarding combined cataract surgery with trabecular microbypass-stent placement. Future prospective studies with larger samples would be valuable for confirming that microbypass-stent placement at the same time of cataract surgery does not negatively impact refractive outcome. Indeed, given that traditionally patients with glaucoma who undergo cataract surgery alone have an increased incidence of refractive surprise, the combined procedure may result in refractive outcomes consistent with cataract surgery alone and concomitantly lower IOP.

To our knowledge, this is the first published report exclusively to evaluate refractive outcomes of cataract surgery combined with trabecular microbypass-stent implantation. The favorable findings of this study suggest the trabecular microbypass stent does not compromise refractive outcomes and can safely be combined with cataract surgery.

\section{What was known}

- MIGS devices are safe and are effective at lowering IOP.

- There is increased incidence of refractive surprise in glaucoma patients undergoing cataract surgery compared to those without glaucoma.

\section{What this paper adds}

- Combining trabecular microbypass-stent implantation with cataract surgery does not alter refractive outcomes in patients with OAG.

- The combined procedure achieves refractive outcomes on par with cataract surgery alone.

\section{Disclosure}

This study was supported by an investigator-initiated trial grant from Glaukos Corp (San Clemente, CA). Drs. Berdahl and 
Ferguson are consultants for Glaukos. Additionally, Dr. Berdahl is a lecturer and consultant for Alcon and Allergan. $\mathrm{He}$ is a consultant for Avedro, Aurea Medical, Bausch and Lomb, Dakota Lions Eye Bank, Gore, Johnson and Johnson, Kala, Kedalion, MELT Pharmaceuticals, MicroOptx, New World Medical, Imprimis, Ocular Theraputix, Orasis, Oyster Point, RxSight, Tear Clear, Vittamed, Zeiss, Vance Thompson Vision, Surface Inc, Omega Ophthalmic, Ocular Surgical Data, Expert Opinion, CorneaGen, and Visionary Ventures. In addition, he reports ownership with Zeiss, Vance Thompson Vision, Surface Inc, Verana Health, Omega Ophthalmic, Ocular Surgical Data, Expert Opinion, and CorneaGen; he is also a patent holder for Imprimis. The authors report no other conflicts of interest in this work.

\section{References}

1. Quigley HA, Broman AT. The number of people with glaucoma worldwide in 2010 and 2020. Br J Ophthalmol. 2006;90:262-267. doi:10.1136/bjo.2005.081224

2. Global prevalence of glaucoma and projections of glaucoma burden through 2040 - ophthalmology. Available from: https://www.aaojournal. org/article/S0161-6420(14)00433-3/fulltext. >Accessed October 15, 2018

3. Lee, PP, Walt JG, Doyle JJ, et al. A multicenter, retrospective pilot study of resource use and costs associated with severity of disease in glaucoma Arch Ophthalmol. 2006;124:12-19. doi:10.1001/archopht.124.1.12

4. Direct costs of glaucoma and severity of the disease: a multinational long term study of resource utilisation in Europe. Available from: https://www. ncbi.nlm.nih.gov/pmc/articles/PMC1772870/. Accessed October 15, 2018

5. Saheb H, Ahmed IIK. Micro-invasive glaucoma surgery: current perspectives and future directions. Curr Opin Ophthalmol. 2012;23:96. doi:10.1097/ICU.0b013e32834ffle7

6. Le K, Saheb H. iStent trabecular micro-bypass stent for open-angle glaucoma. Clin Ophthalmol. 2014;8:1937-1945.

7. Voskanyan L, García-Feijoó J, Belda JI, Fea A, Jünemann A, Baudouin C. Prospective, unmasked evaluation of the iStent ${ }^{\mathbb{B}}$ Inject system for open-angle glaucoma: synergy trial. $A d v$ Ther. 2014;31:189-201. doi:10.1007/s12325-014-0095-y

8. Buchacra O, Duch S, Milla E, Stirbu O. One-year analysis of the iStent trabecular microbypass in secondary glaucoma. Clin Ophthalmol. 2011;5:321-326.

9. Vandewalle E, Zeyen T, Stalmans I. The iStent trabecular microbypass stent: a case series. Bull Soc Belge Ophtalmol. 2009:23-29.

10. Craven ER, Katz LJ, Wells JM, Giamporcaro JE. Cataract surgery with trabecular micro-bypass stent implantation in patients with mildto-moderate open-angle glaucoma and cataract: two-year follow-up. $J$ Cataract Refract Surg. 2012;38:1339-1345. doi:10.1016/j. jcrs.2012.03.025

11. Randomized evaluation of the trabecular micro-bypass stent with phacoemulsification in patients with glaucoma and cataract scienceDirect. Available from: https://www.sciencedirect.com/ science/article/pii/S0161642010007438. Accessed October 15, 2018

12. Arriola-Villalobos P, Martínez-de-la-Casa JM, Díaz-Valle D, Fernández-Pérez C, García-Sánchez J, García-Feijoó J. Combined iStent trabecular micro-bypass stent implantation and phacoemulsification for coexistent open-angle glaucoma and cataract: a long-term study. Br J Ophthalmol. 2012;96:645-649. doi:10.1136/bjophthalmol-2011-300218
13. Spiegel D, García-Feijoó J, García-Sánchez J, Lamielle H. Coexistent primary open-angle glaucoma and cataract: preliminary analysis of treatment by cataract surgery and the iStent trabecular micro-bypass stent. Adv Ther. 2008;25:453-464. doi:10.1007/s12325-008-0062-6

14. Manoharan N, Patnaik JL, Bonnell LN, et al. Refractive outcomes of phacoemulsification cataract surgery in glaucoma patients. $J$ Cataract Refract Surg. 2018;44:348-354. doi:10.1016/j.jcrs.2017.12.024

15. Hugkulstone CE. Changes in keratometry following trabeculectomy. Br J Ophthalmol. 1991;75:217-218. doi:10.1136/bjo.75.7.440

16. Cunliffe IA, Dapling RB, West J, Longstaff S. A prospective study examining the changes in factors that affect visual acuity following trabeculectomy. Eye. 1992;6:618-622. doi:10.1038/eye.1992.133

17. Rosen WJ, Mannis M, Brandt JD. The effect of trabeculectomy on corneal topography. Ophthalmic Surg Lasers Imaging Retina. 1992;23:395-398.

18. Claridge KG, Galbraith JK, Karmel V, Bates AK. The effect of trabeculectomy on refraction, keratometry and corneal topography. Eye. 1995;9:292-298. doi:10.1038/eye.1995.57

19. El-Saied HMA, Foad PH, Eldaly MA, Abdelhakim MASE. Surgically induced astigmatism following glaucoma surgery in Egyptian patients. J Glaucoma. 2014;23:190-193. doi:10.1097/IJG.0000000000000035

20. Zhang N, Tsai PL, Catoira-Boyle YP, et al. The effect of prior trabeculectomy on refractive outcomes of cataract surgery. Am J Ophthalmol. 2013;155:858-863. doi:10.1016/j.ajo.2012.11.023

21. Muallem MS, Nelson GA, Osmanovic S, Quinones R, Viana M, Edward DP. Predicted refraction versus refraction outcome in cataract surgery following trabeculectomy. J Glaucoma. 2009;18:284-287. doi:10.1097/IJG.0b013e318184567b

22. Francis, BA, Wang M, Lei H, et al. Changes in axial length following trabeculectomy and glaucoma drainage device surgery. $\mathrm{Br} J$ Ophthalmol. 2005;89:17-20. doi:10.1136/bjo.2004.059121

23. Tzu JH, Shah CT, Galor A, Junk AK, Sastry A, Wellik SR. Refractive outcomes of combined cataract and glaucoma surgery. J Glaucoma. 2015;24:161-164. doi:10.1097/01.ijg.0000435773.20279.56

24. Hammel N, Lusky M, Kaiserman I, Robinson A, Bahar I. Changes in anterior segment parameters after insertion of Ex-PRESS miniature glaucoma implant. J Glaucoma. 2013;22:565-568. doi:10.1097/ IJG.0b013e31824d4fa 1

25. Flowers B. (2018). Effect of Supraciliary Microstent Implantation Concurrent with Cataract Surgery on the Accuracy of IOL Calculations in Patients with Open-Angle Glaucoma. ASCRS - 2018 ASCRS ASOA annual meeting. Available from: https://ascrs.confex. com/ascrs/18am/meetingapp.cgi.

26. Primary open-angle glaucoma preferred practice pattern ${ }^{\circledR}$ guidelines ophthalmology. Available from: https://www.aaojournal.org/article/ S0161-6420(15)01276-2/fulltext. Accessed October 15, 2018

27. Astigmatism double angle plot tool | ASCRS. Available from: http://ascrs. org/astigmatism-double-angle-plot-tool. Accessed November 6, 2018

28. Gale RP, Saldana M, Johnston RL, Zuberbuhler B, McKibbin M. Benchmark standards for refractive outcomes after NHS cataract surgery. Eye. 2009;23:149-152. doi:10.1038/sj.eye.6702954

29. Brogan K, Diaper CJM, Rotchford AP. Cataract surgery refractive outcomes: representative standards in a National Health Service setting. Br J Ophthalmol. 2018. doi:10.1136/bjophthalmol-2018-312209

30. Simon, SS, Chee YE, Haddadin RI, et al. Achieving target refraction after cataract surgery. Ophthalmology. 2014;121:440-444. doi:10.1016/ j.ophtha.2013.09.022

31. Sheybani A, Saboori M, Kim JM, Gammon H, Lee AY, Bhorade AM. Effect of endoscopic cyclophotocoagulation on refractive outcomes when combined with cataract surgery. Can $J$ Ophthalmol. 2015;50:197-201. doi:10.1016/j.jcjo.2015.03.006

32. Luebke J, Boehringer D, Neuburger $M$, et al. Refractive and visual outcomes after combined cataract and trabectome surgery: a report on the possible influences of combining cataract and trabectome surgery on refractive and visual outcomes. Graefes Arch Clin Exp Ophthalmol. 2015;253:419-423. doi:10.1007/ s00417-014-2881-2 


\section{Publish your work in this journal}

Clinical Ophthalmology is an international, peer-reviewed journal covering all subspecialties within ophthalmology. Key topics include: Optometry; Visual science; Pharmacology and drug therapy in eye diseases; Basic Sciences; Primary and Secondary eye care; Patient Safety and Quality of Care Improvements. This journal is indexed on PubMed
Central and CAS, and is the official journal of The Society of Clinical Ophthalmology (SCO). The manuscript management system is completely online and includes a very quick and fair peer-review system, which is all easy to use. Visit http://www.dovepress.com/ testimonials.php to read real quotes from published authors.

Submit your manuscript here: https://www.dovepress.com/clinical-ophthalmology-journal 